\title{
CCL21 induces extensive intratumoral immune cell infiltration and specific anti-tumor cellular immunity
}

\author{
HETH R. TURNQUIST ${ }^{1,2,4}$, XUEDE LIN ${ }^{1}$, ABDELKADER E. ASHOUR ${ }^{1,3}$, MICHAEL A. HOLLINGSWORTH ${ }^{1-3}$, \\ RAKESH K. SINGH ${ }^{2}$, JAMES E. TALMADGE ${ }^{2}$ and JOYCE C. SOLHEIM ${ }^{1-3}$ \\ ${ }^{1}$ Eppley Institute for Research in Cancer and Allied Diseases; Departments of ${ }^{2}$ Pathology and Microbiology, \\ ${ }^{3}$ Biochemistry and Molecular Biology, University of Nebraska Medical Center, Omaha, NE, USA
}

Received October 20, 2006; Accepted December 1, 2006

\begin{abstract}
Chemokines are vital messengers that regulate immune cell activity. The chemokine CCL21 is normally expressed in secondary lymphoid organs and acts as a chemoattractant for several populations of immune cells. Herein, we report that intratumoral CCL21 administration recruited significant numbers of immune cells into murine pancreatic tumors and inhibited tumor growth. Detailed flow cytometric and confocal analysis of CCL21-treated tumor cell isolates revealed increased lymphoid-related dendritic cells (IDC) and myeloid $\mathrm{DC}(\mathrm{mDC})$, naïve and mature $\mathrm{T}$ cells, natural killer (NK) cells, and NKT cells infiltrating the tumor mass. Furthermore, CCL21 intratumoral treatments resulted in significant tumor growth inhibition in wild-type (WT) C57BL/6 mice, but no therapeutic benefit was observed in C57BL/6 RAG2 $2^{-/} P \mathrm{fp}^{-/}$mice, suggesting that the growth inhibition observed was immunologically mediated. CCL21 intratumoral injections generated immune responses that were tumor-specific and that could be transferred to naïve animals via splenocytes. In addition, intratumoral injection of CCL21 into pancreatic tumors reduced the growth of distant
\end{abstract}

Correspondence to: Dr Joyce Solheim, Eppley Institute for Research in Cancer and Allied Diseases, University of Nebraska Medical Center, 986805, Omaha, NE 68198-6805, USA

E-mail: jsolheim@unmc.edu

Present address: ${ }^{4}$ Thomas E. Starzl Transplantation Institute, Department of Surgery, Division of Transplant Immunology, University of Pittsburgh, Pittsburgh, PA, USA

Abbreviations: DC, dendritic cell; NK, natural killer; IL, interleukin; s.c., subcutaneous; FITC, fluorescein isothiocyanate; PE, phycoerythrin; APC, allophycocyanin; Pfp, perforin; mDC, myeloid DC; IDC, lymphoid-related DC; pDC, plasmacytoid DC; 3LL, Lewis lung carcinoma; WT, wild-type; IF, immunofluorescent

Key words: CCL21, chemokine, dendritic cell, pancreatic cancer, tumor immunology tumors as well as treated tumors. Thus, these data demonstrate in a pancreatic tumor model that intratumoral administration of CCL21 can cause significant immune cell infiltration of the tumor mass, delay growth of treated tumors, and generate a tumor-specific cellular immune response.

\section{Introduction}

CCL21 acts in the secondary lymphoid organs as a chemoattractant (1). The CCL21R, CCR7, is found on diverse populations of $\mathrm{T}$ cells and maturing $\mathrm{MDC}$ and $\mathrm{IDC}$, and has been detected on NK and NKT cells (2-9). CCR7 expression allows migration along CCL21 gradients formed on the extracellular matrix of endothelial cells of the lymphoid organs, which constitutively secrete CCL21 $(10,11)$. Besides its role in chemotaxis, CCL21 can induce endocytosis by mature DC, which may facilitate DC cross-presentation of antigen (12). In addition, CCL21, acting on vascular endothelial cells via binding to an alternative chemokine receptor, CXCR3, has been reported to have angiostatic effects in mice $(13,14)$.

The ability of CCL21 to act as a chemoattractant for DC and $\mathrm{T}$ cells has recently led to evaluations of its therapeutic efficacy. Transfection of the CCL21 cDNA into a colon carcinoma cell line reduced tumor growth in both immunocompetent and nude mice, through immune and angiostatic mechanisms (14). In murine models of melanoma and mammary cancer, a daily intratumoral injection of recombinant murine CCL21 for three days inhibited tumor growth (15). Intratumoral CCL21 therapy in murine lung cancer models reduced tumor burdens, increased tumor infiltration by $\mathrm{T}$ cells and DC, and elevated tumor levels of interferon- $\gamma$, CXCL10, CXCL9, granulocyte macrophage-colony stimulating factor, and interleukin (IL)-12 (16-19). In conjunction, CCL21 treatment of murine lung tumors decreased the levels of prostaglandin E2, vascular endothelial growth factor, IL-10, and transforming growth factor- $\beta$ in the injected tumors $(16,17)$. Intratumoral, intranodal, and s.c. administration of DC modified to express CCL21 has also demonstrated promise in mouse models of cancer $(15,19,20)$.

Pancreatic cancer arises asymptomatically and is often diagnosed late in tumor development. Since current therapies do not prolong survival, the median lifespan after diagnosis is $<6$ months $(21,22)$. Recently, pancreatic tumor samples from 
patients who had undergone surgical resection revealed a direct correlation between the intratumoral numbers of $\mathrm{CD}^{+}$and $\mathrm{CD}^{+} \mathrm{T}$ cells and overall survival (23). Furthermore, samples with infiltrating $\mathrm{CD}^{+}{ }^{+}$and $\mathrm{CD} 8^{+} \mathrm{T}$ cells also displayed increased numbers of DC (23). This association has been substantiated by separate clinical findings demonstrating that an increase in the number of DC infiltrating a pancreatic tumor is associated with improved prognosis, and that pancreatic adenocarcinomas typically display a lack of infiltrating DC (24). The recruitment of DC to pancreatic tumors would be expected to improve prognosis by increasing DC phagocytosis of apoptotic and necrotic tumor cells and enhancing the presentation of relevant tumor antigen $(25,26)$. Furthermore, the stimulation of local immune cells by infiltrating mature DC, via cytokine secretion and displayed stimulatory molecules, would also be expected to facilitate anti-tumor responses.

We hypothesized that intratumoral injections of CCL21 could attract immune cells, including DC and T cells, and inhibit tumor growth of established murine pancreatic tumors. In our studies, we found that pancreatic tumors treated with intratumoral CCL21 became infiltrated with significantly increased numbers of $\mathrm{CD}^{+} \mathrm{T}$ cells, $\mathrm{NK}$ cells, NKT cells, and both IDC and $\mathrm{mDC}$. T cell and DC infiltration were observed especially in perivascular foci within the treated tumors. Intratumoral treatment with CCL21 inhibited the growth of treated tumors in WT mice, but it was not efficacious in $R A G 2^{-/} P f^{-/-}$ mice, suggesting an immunological mechanism underlies CCL21 therapeutic activity in this tumor model. Furthermore, the immune reactivity generated by intratumoral administration of CCL21 was effective against distant tumors, could be adoptively transferred, and was tumor-specific. These results support the further investigation of CCL21 as a potential immunotherapy for pancreatic cancer.

\section{Materials and methods}

Animals, tumor model, and CCL21. Female C57BL/6 mice, 6-8 weeks of age, were purchased from the National Cancer Institute (Frederick, MD) and female $R A G 2^{-/} \mathrm{Pfp}^{-/-}$mice were obtained from Taconic (Germantown, NY). All mice were 10 weeks of age at the initiation of studies. The animals were housed in pathogen-free conditions and experiments were carried out under an approved institutional animal care and use protocol.

For assessment of CCL21-induced anti-tumor responses, Panc02 cells were thawed from a bank of low passage, parental stock cells and passaged only twice before injection. The cells were cultured in McCoy's 5A media supplemented with 10\% FBS, $10 \mathrm{mM}$ HEPES, $2 \mathrm{mM}$ L-glutamine, penicillin $(50 \mathrm{U} / \mathrm{ml})$, and streptomycin $(50 \mu \mathrm{g} / \mathrm{ml})$ in $5 \% \mathrm{CO}_{2}$. All culture reagents were purchased from Invitrogen (Grand Island, NY). Recombinant murine CCL21 was obtained from PeproTech (Rocky Hill, NJ), and was delivered in $50 \mu 1$ sterile PBS with $0.05 \%$ normal mouse serum (Jackson ImmunoResearch Laboratories, Inc., West Grove, PA). Control PBS injections also included $0.05 \%$ normal mouse serum.

Tumor inhibition. To compare the response of WT and $R A G 2^{-/ P f p^{-/}}$mice to CCL21 tumor therapy, C57BL/6 or

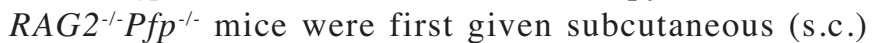

injections of $1 \times 10^{6}$ Panc02 cells dorsally between the scapulae. Once tumors were palpable (mean $12 \mathrm{~mm}^{3}$, day 20), the mice were randomized into treatment cohorts ( 8 mice/group). At the time of treatment, the tumors were not significantly different in size between treatment and control groups $(p=0.78$ for the two groups of $\mathrm{C} 57 \mathrm{BL} / 6$ mice and $\mathrm{p}=0.73$ for the two groups of $R A G 2^{-/} P f p^{-/}$mice). Treatments of either $1 \mu \mathrm{g}$ CCL21 or PBS were delivered intratumorally on days 1, 2, and 3, followed by 4 days without treatment, and again for 3 consecutive days (on days 8,9, and 10). Tumors were measured with calipers in two perpendicular directions twice per week.

To analyze effects of CCL21 intratumoral treatment on growth of untreated tumors, Panc02 tumor cells were injected subcutaneously into C57BL/6 mice ( $\mathrm{n}=8-10$ /group) on both flanks, and once tumors were palpable (at approximately day 20) right flank tumors (mean volume $18.5 \mathrm{~mm}^{3}$ ) were injected daily with CCL21 or PBS for 2 cycles of 3 daily treatments, 4 days apart. The left flank tumors (mean volume $6.0 \mathrm{~mm}^{3}$ ) of both groups were not treated. The change in mean tumor volume over time for treated and untreated tumors was monitored.

Winn assay. Groups of C57BL/6 mice $(\mathrm{n}=5-14)$ were injected s.c. above the scapulae with $1 \times 10^{6} \mathrm{Panc} 02$ cells. Once these tumors were palpable, mice were randomized into groups that did not differ significantly in tumor volume and treated as described previously (PBS n=6-10; CCL21 n=10-14). On day 11 or 13 post-treatment initiation, the animals were sacrificed. Splenic leukocytes obtained from PBS- or CCL21-treated mice were pooled, mixed with Panc02 or 3LL cells, and injected s.c. above the scapulae of naïve C57BL/6 mice $\left(5 \times 10^{7}\right.$ splenocytes: $5 \times 10^{5}$ tumor cells per mouse). Time to tumor development and tumor growth rate were recorded.

Histological and immunohistochemical analysis. C57BL/6 mice were given s.c. tumors above the scapulae as described above. Randomized cohorts of mice $(n=2-4)$ with tumors not significantly different in size received intratumoral injections of CCL21 or PBS. On the fifth day following the last treatment (day 15), animals were sacrificed, and tumors and marginal tissue were resected. The tumors were bisected at the midline, half was embedded in Tissue Freezing Media (Triangle Biomedical Sciences, Durham, NC) and flash frozen in liquid nitrogen, and the opposing half was fixed in $10 \%$ buffered formalin, paraffin-embedded, sectioned, and stained with hematoxylin and eosin. Frozen tumor samples were cryosectioned and fixed in ice cold 1:1 acetone:methanol. Nonspecific binding was blocked with $10 \%$ normal goat serum (Vector Laboratories, Burlingame, CA) and then the sections were incubated with antibodies for $2 \mathrm{~h}$ at room temperature. Antibodies were used that recognize CD3 (Rabbit IgG; DakoCytomation, Carpinteria, CA) and CD205 (NLDC-145, Rat $\mathrm{IgG}_{2 \mathrm{a}}$; Serotec, Oxford, UK), MHC class II (M5/114.15.2, Rat $\mathrm{IgG}_{2 \mathrm{~b}}$; BD PharMingen, San Diego, CA), and Ly-49G2 (Rat $\mathrm{IgG}_{2 \mathrm{a}}$; BD PharMingen). Following the incubation, sections were overlaid with species-specific secondary antibody and incubated at room temperature for $1 \mathrm{~h}$. The antibodies were cross-linked with $2 \%$ paraformaldehyde, the slides were coverslipped, and fluorescence images of the sections were obtained using a Zeiss Confocal Microscope LSM410. 

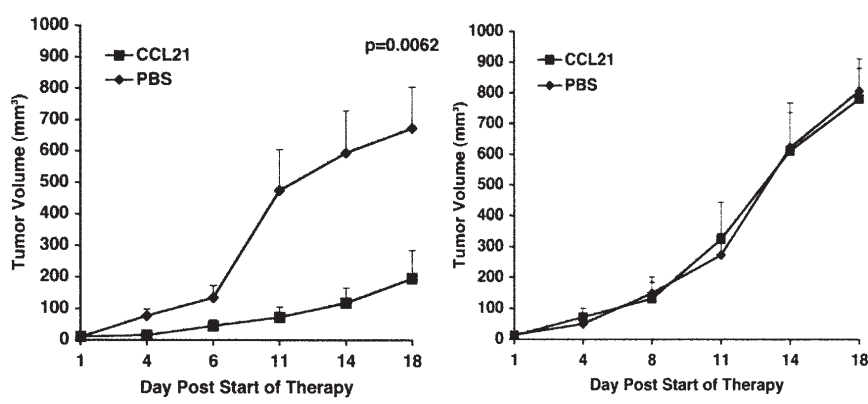

Figure 1. Tumor growth was inhibited by intratumoral CCL21 treatment of Panc02 tumors in WT mice (A) but not in $R A G 2^{-/} P f p^{-/}$mice (B). Cohorts of mice were treated on days $1,2,3,8,9$, and 10 with intratumoral injections of CCL21 $(\boldsymbol{\bullet}, \mathrm{n}=8)$ or PBS $(\bullet ; n=8)$. The graphs display the changes in tumor volumes over time, with the first day of treatment as day 1 . Tumor volumes were calculated as length $/ 2 \mathrm{x}$ width ${ }^{2}$, and were averaged across treatment groups. Bars represent the standard error of the mean.

Tumor harvest and flow cytometric analysis of infiltrating cells. Panc02 tumors were treated as described above with CCL21 or PBS ( $n=2-4$ mice per treatment cohort). Twenty-four hours after the last treatment (day 11), the tumors were resected and non-necrotic tumor tissue was minced. Following treatment with collagenase (200 U/ml; Sigma-Aldrich, St. Louis, MO) and deoxyribonuclease I ( $270 \mathrm{Ku} / \mathrm{ml}$; Sigma-Aldrich) at $37^{\circ} \mathrm{C}$ for $1 \mathrm{~h}$, the mononuclear cells were isolated with Lympholyte ${ }^{\circledR}-\mathrm{M}$ (Cedarlane, Hornby, Ontario), and stained for flow cytometric analysis. The antibodies used were labeled with fluorescein isothiocyanate (FITC), biotin, or phycoerythrin (PE) (BD PharMingen). Biotinylated antibodies were revealed with allophycocyanin (APC)-streptavidin (Molecular Probes, Eugene, OR). The following antibodies were utilized in the flow cytometric analysis (clone designations and isotypes are indicated): CD3 (145-2C11, Armenian hamster IgG1, $)$, CD4 (H129.19, Rat $\left.\operatorname{IgG}_{2 \mathrm{a}}, \kappa\right), \mathrm{CD} 8 \alpha$ (53-6.7, Rat $\left.\operatorname{IgG}_{2 \mathrm{a}}, \kappa\right), \mathrm{CD} 62 \mathrm{~L}$ (MEL-14, Rat $\left.\operatorname{IgG}_{2 \mathrm{a}}, \kappa\right)$, NK1.1 (PK136, Mouse $\left.\operatorname{IgG}_{2 \mathrm{a}}, \kappa\right)$, CD11c (HL3, Armenian hamster, $\operatorname{IgG}_{1}, \lambda$ ), CD11b (M1/70, Rat $\left.\mathrm{IgG}_{2 \mathrm{~b}}, \kappa\right)$, B220 (RA3-6B2, Rat IgG $\left.\mathrm{Iga}_{2 \mathrm{a}}, \kappa\right)$, CD25 (PC61, Rat $\mathrm{IgG}_{1}, \lambda$ ), and Gr-1 (RB6-8C5, Rat $\left.\operatorname{IgG}_{2 \mathrm{~b}}, \kappa\right)$. Data on the stained samples were acquired with a FACSCalibur flow cytometer (BD ImmunoCytometry Systems, San Jose, CA), and gating on forward and side scatter was performed before analysis of antibody staining. Per sample, 30,000-100,000 events were collected, and the data were analyzed with Attractors, CellQuest (BD ImmunoCytometry Systems), or FCSPress 1.4 (Ray Hicks, Cambridge, UK).

Statistical analysis. Statistical differences between treatment groups in the percentage of animals remaining tumor-free were calculated using the log-rank test in the GraphPad Prism 2.0C Software package (GraphPad Software, Inc., San Diego, CA). Determination of significant differences in tumor growth over time was performed with the JMP IN 4.04 Statistical Package (SAS Institute Inc., Cary, NC) utilizing repeated measure multivariate analysis of variance (MANOVA). The Student's t-test in JMP IN 4.04 was used to determine statistical significance $(\mathrm{p}<0.05)$ for differences in tumor volume at
A. Right Flank Tumor Volumes

B. Uninjected Left Flank Tumor Volumes
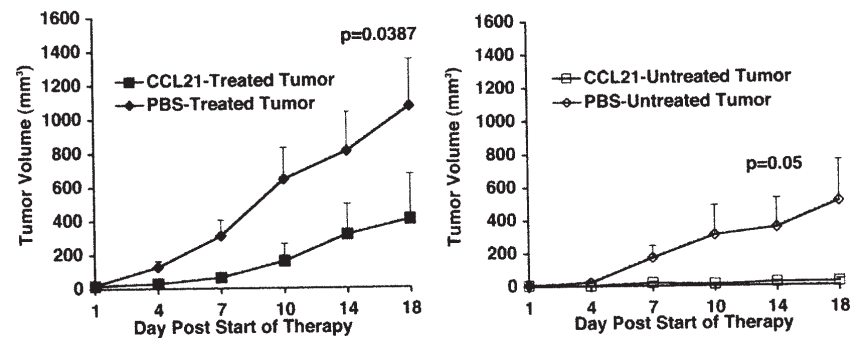

Figure 2. CCL21 inhibited the growth of distant, untreated Panc02 tumors. Panc02 tumor cells were injected subcutaneously into C57BL/6 mice ( $\mathrm{n}=8-10$ / group) on both flanks, and after the tumors developed the right flank tumors were injected daily with CCL21 or PBS for 2 cycles of 3 daily treatments, at 4 days apart. The left flank tumors of both groups were not treated with CCL21 or PBS. The sizes of tumors over time for both treated (A) and untreated (B) tumors were monitored. Tumor volumes were calculated as length $/ 2 \mathrm{x}$ width ${ }^{2}$, and were averaged for each treatment group. Bars represent the standard error of the mean.

independent time points or in the number of tumor-infiltrating immune cells with separate phenotypes.

\section{Results}

CCL21 injection slowed the growth of treated tumors. To determine whether CCL21 has potential therapeutic efficacy against pancreatic cancer, we examined the effect of intratumoral CCL21 injections against tumors arising from s.c. injected Panc02 cells. Panc02 is a C57BL/6-derived pancreatic cancer cell line (27). Following the development of tumors (12 $\mathrm{mm}^{3}$ in mean volume) in WT C57BL/6 mice, daily intratumoral injections of CCL21 or PBS for 3 days in 2 cycles, spaced 4 days apart, were initiated. As shown in Fig. 1A, intratumoral CCL21 treatment significantly inhibited tumor growth in WT C57BL/6 mice, beginning on day 4 following the initial treatment. Maximal inhibition occurred on days 11-14, at which time CCL21-treated tumors averaged $85 \%$ less volume than tumors treated with PBS for the same time period. CCL21 toxicity was not likely to be responsible for the decreased tumor growth, as we found that CCL21 did not reduce the growth rate of Panc 02 in vitro at $10 \mu \mathrm{g} / \mathrm{ml}$, which is $\sim 1000$-fold greater than the concentration of CCL21 in the injected mouse tumors (data not shown).

To investigate the mechanism for the observed CCL21 therapeutic activity, CCL21 or PBS was also injected into

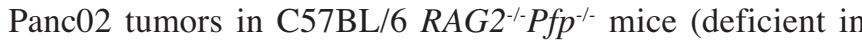
functional T, B, and NK cells), just as described above for WT C57BL/6 mice. On day 14 after the initiation of therapy, the volumes of CCL21-treated tumors from $R A G 2^{-/} P f p^{-/}$mice were very similar to those of tumors from $\mathrm{C} 57 \mathrm{BL} / 6$ and $R A G 2^{-/} P f p^{-/}$ PBS-treated mice (Fig. 1B). These results suggest that the tumor growth inhibition that was observed in C57BL/6 mice was immunologically mediated.

CCL21 reduced the rate of distant as well as local tumor growth in a pancreatic tumor model. To analyze distant effects of CCL21 intratumoral treatment, we injected Panc02 tumor cells into mice at two separate sites, and treated one of the resultant tumors. Specifically, subcutaneous tumors were 

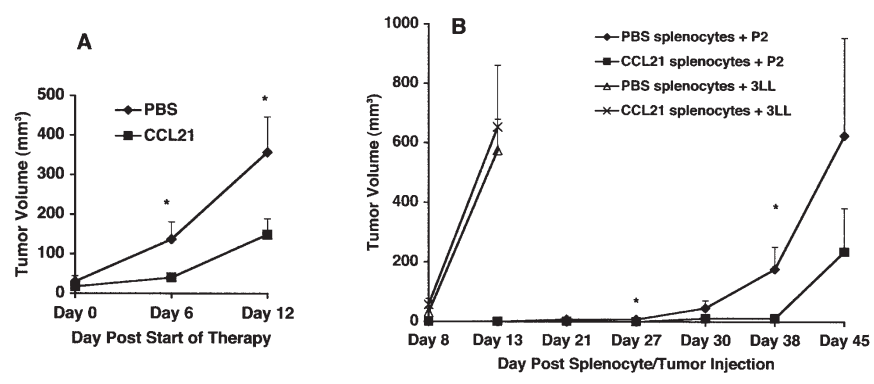

C

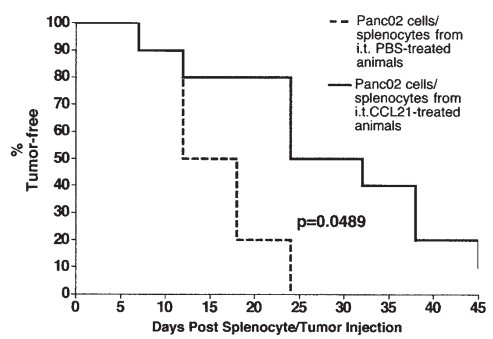

Figure 3. Systemic anti-tumor responses generated by CCL21 treatment of Panc02 tumors were tumor-specific and transferable via splenocytes to naïve animals. Upon development of palpable s.c. Panc02 tumors in mice, intratumoral CCL21 $(n=10-14)$ or PBS $(n=6-10)$ was injected on days 1,2 , $3,8,9$, and 10 . On day 13 , the animals were sacrificed and splenocytes were isolated, pooled, mixed with either Panc02 or 3LL tumor cells, and injected s.c. into naïve $\mathrm{C} 57 \mathrm{BL} / 6$ females $\left(\mathrm{n}=4-10 ; 5 \times 10^{7}\right.$ splenocytes: $5 \times 10^{5}$ tumor cells). (A) Change in CCL21- or PBS-treated tumor volumes in animals from which splenocytes were derived. (B) Comparison of tumor growth in naïve C57BL/6 given s.c. tumor cells (Panc02 or 3LL) mixed with splenocytes from PBS- or CCL21-treated animals. (C) Comparison of the percentage of animals remaining tumor-free following injection with mixed Panc02 tumor cells and splenocytes from CCL21- or PBS-treated animals. The data are representative of one of the two independent experiments.

first established in both flanks of C57BL/6 mice by injection of Panc02 cells $\left(2 \times 10^{6}\right.$ cells in the right flank and $1 \times 10^{6}$ cells in the left flank). After development of the tumors, the right flank tumors (mean volume $18.5 \mathrm{~mm}^{3}$ ) were injected daily with CCL21 or PBS for 2 cycles of 3 daily treatments, given 4 days apart. The left flank tumors (mean volume $6.0 \mathrm{~mm}^{3}$ ) of both groups received no injections. Fig. 2 depicts the change in mean tumor volume over time for treated (panel A) and untreated (panel B) tumors. Intratumoral CCL21 injection significantly inhibited the growth of tumors in C57BL/6 mice ( $\mathrm{p}=0.0387$ through day 18 , with 2.5-5.0-fold less tumor volume through day 18) (Fig. 2A). Moreover, tumor inhibition was not limited to the treated tumor, but the growth of the second, non-injected tumor was also significantly slowed $(\mathrm{p}=0.05$ through day 14) (Fig. 2B). For mice that had received CCL21 injections in the right flank tumors, a 14-fold growth rate reduction was observed for the untreated left flank tumors through day 18. These data suggest that CCL21 treatment initiates immune responses capable of acting both locally against the treated primary pancreatic tumor and systemically against a spatially distant tumor.

CCL21 effects were tumor-specific and transferable to naïve animals. To further examine whether the observed delay in Panc02 tumor growth following intratumoral CCL21 injection was accompanied by immune responses that were systemic and tumor-specific, splenocytes from tumor-bearing mice that had been treated intratumorally with CCL21 or PBS were utilized in Winn assays (28). Tumor volumes of animals treated with intratumoral CCL21 or PBS were monitored over time (Fig. 3A), and then the mice were sacrificed and total splenocytes were isolated from each group. When splenocytes were injected into C57BL/6 mice along with Panc02 or syngeneic 3LL tumor cells (at 100:1 splenocytes:tumor cells), the splenocytes from CCL21-treated animals, but not PBS-treated animals, significantly inhibited Panc02 (but not 3LL) tumor growth (Fig. 3B) and delayed tumor onset (Fig. 3C). Thus, these findings demonstrate that a specific, systemic immune response to Panc02 tumors developed following CCL21 intratumoral treatment.

CCL21 injection increased leukocyte infiltration. Hematoxylin and eosin-stained tumor sections from corresponding areas of CCL21- or PBS-treated tumors were examined microscopically to determine the effect of injections of CCL21 on inflammatory cell infiltration. Fifteen days following the initiation of CCL21 or control PBS treatments of matched tumors, the treated tumors and marginal tissues were resected. Sections from a medial plane at the maximal tumor circumference revealed that the PBS-treated tumors (Fig. 4A) had uniform fields of anaplastic tumor cells, infrequently infiltrated with individual inflammatory cells. In contrast to PBS-treated tumors, corresponding regions of CCL21-treated tumors (Fig. 4B) had increased overall inflammatory cell infiltrate and foci of leukocytes around tumor vasculature. Visualization of the vasculature by immunohistochemical staining revealed that the CCL21-treated tumors had a greatly reduced vascular density compared to PBS-treated controls (data not shown), which could be related to anti-angiogenic effects or simply to the reduced development of the CCL21-treated tumors.

Phenotype of the tumor infiltrate induced by intratumoral CCL21 injection. To identify tumor-infiltrating leukocytes, we performed immunofluorescent (IF) and confocal microscopy on cryosections from PBS- and CCL21-treated tumors, using antibodies recognizing murine T cells, NK cells, and DC. PBS-treated tumor sections at day 15 post-treatment initiation had few infiltrating $\mathrm{CD}^{+} \mathrm{T}$ cells (Fig. 5A). In contrast, CCL21-treated tumor sections had increased numbers of $\mathrm{CD}^{+}$ cells spread diffusely throughout the entire section, and the lymphoid-like foci were highly enriched for T cells (Fig. 5B).

By staining PBS-treated tumor sections with antibodies for DC markers, including CD205 (a protein expressed at high levels on murine DC, especially IDC) (29), we found very few infiltrating DC in the PBS-treated tumor sections (Fig. 5C). Similar results for PBS-treated tumors were obtained with antibodies against CD11c and MHC class II (data not shown). In the CCL21-treated tumor sections, more DC were detected (by anti-CD205 and anti-CD11c antibodies), and they were found in areas of immune cell aggregation co-localized with $\mathrm{CD}^{+} \mathrm{T}$ cells and NK cells (Fig. 5D and E). Furthermore, staining CCL21-treated tumor samples with antibodies specific for both $\mathrm{CD}^{+} \mathrm{T}$ cells and $\mathrm{MHC}$ class $\mathrm{II}^{+}$cells (presumably mostly DC) and analyzing the samples by confocal microscopy revealed some co-localization of T cells with MHC class $\mathrm{II}^{+}$cells (Fig. 5F and G). 

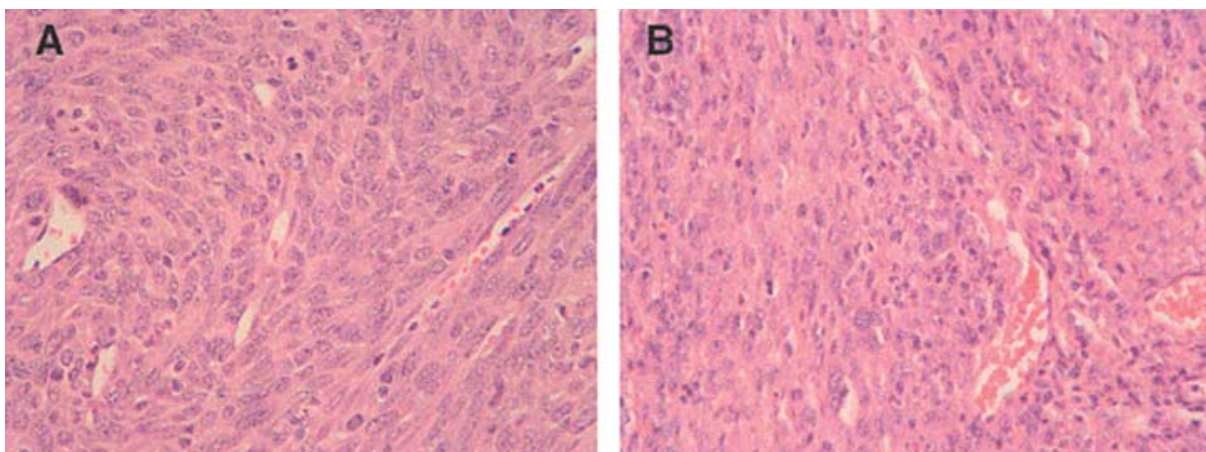

Figure 4. Panc02 tumors treated intratumorally with CCL21 exhibited an increased number of infiltrating leukocytes. Photomicrographs (x400) show representative areas of tumor sections taken from a medial plane through the maximum tumor circumference. Hematoxylin and eosin staining of these sections from established s.c. dorsal tumors treated with (A) PBS or (B) CCL21 $(1 \mu \mathrm{g})$ on days 1,2,3,8,9, and 10 and resected 5 days after the last treatment.
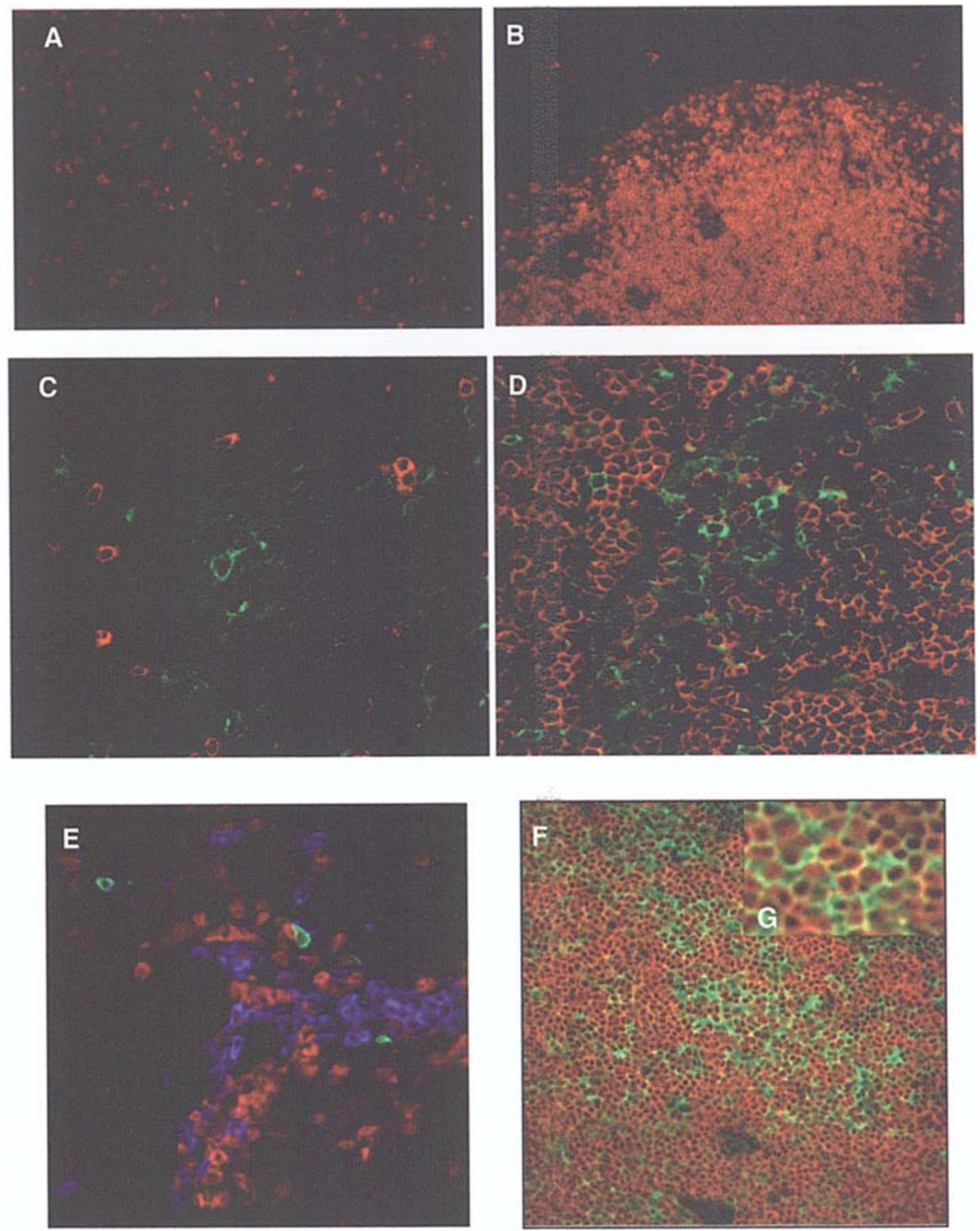

Figure 5. CCL21-treated tumors contained large numbers of co-localized infiltrating T cells, DC, and NK cells. Cryosections of s.c. Panc02 tumors treated with CCL21 or PBS were immunostained using antibodies recognizing the pan T cell marker CD3 (red; $A \rightarrow G)$, several surface molecules found on DC: CD205 (green; C and D), CD11c (blue; E), or MHC class II (green; F and G), and the NK cell marker Ly-49G2 (green; E) and were examined by confocal microscopy. (F and G) Co-localization of $\mathrm{CD}^{+}$cells and MHC class $\mathrm{II}^{+}$cells is indicated by overlapping color (yellow). (G) Digital magnification (x1200) of an area containing $\mathrm{CD}^{+}$cells and $\mathrm{MHC}$ class $\mathrm{II}^{+}$cells from $(\mathrm{F})$ is presented in the upper right corner inset. 
A

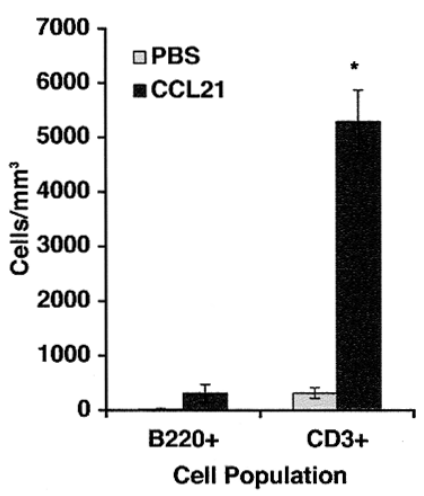

B

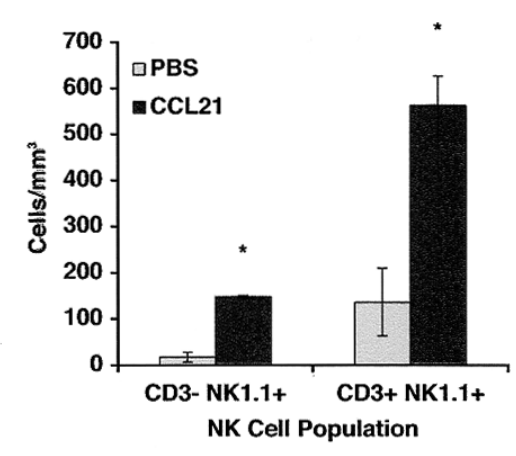

C

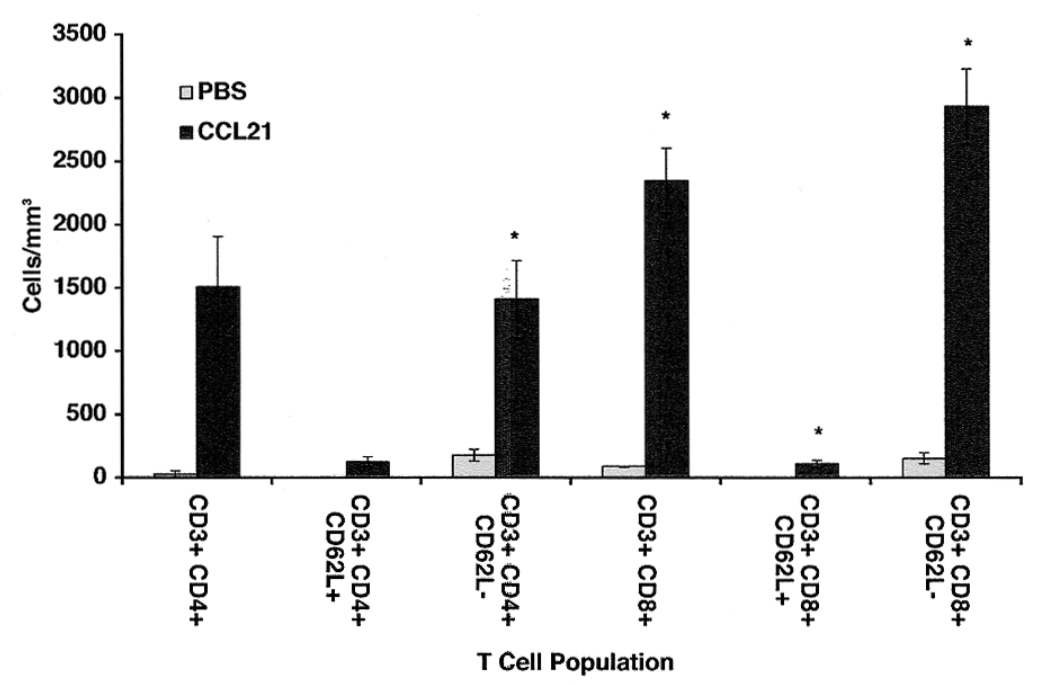

Figure 6. Intralesional CCL21 injections quantitatively increased T and NK cell infiltration of tumors. For quantitative analysis of tumor-infiltrating lymphocytes, Panc02 tumors from PBS- or CCL21-treated mice were resected $24 \mathrm{~h}$ after the completion of CCL21 or PBS treatments. Following tumor measurement, digestion, and mononuclear cell purification, isolated cells were stained and evaluated for expression of lineage-associated phenotypes by multi-color flow cytometry. To normalize for differences in tumor sizes between PBS- and CCL21-treated groups at the time of sacrifice, the average total cells $/ \mathrm{mm}^{3}$ was obtained after calculating the cells $/ \mathrm{mm}^{3}$ for each mouse. Data presented are representative of findings obtained in three independent experiments (with $n=2-4$ mice in each treatment cohort used in each experiment). Significant differences from PBS controls are indicated by asterisks. (A) Significant differences in the number of CD3+ cells (mostly T cells), but not B220+ cells (mostly B cells) were observed between PBS and CCL21 treatment groups. (B) Both NK cells (CD3-NK1.1 $)$ and NKT cells $\left(C D 3^{+} \mathrm{NK} 1.1^{+}\right)$were more numerous in CCL21-treated tumors. (C) Treatment with CCL21 significantly increased the number of $\mathrm{CD}^{+} \mathrm{CD} 4^{+} \mathrm{CD} 62 \mathrm{~L}^{-} \mathrm{T}$ cells, $\mathrm{CD} 4^{+} \mathrm{CD} 25^{+} \mathrm{T}$ cells, $\mathrm{CD} 3^{+} \mathrm{CD} 8^{+} \mathrm{T}$ cells, $\mathrm{CD}^{+} \mathrm{CD} 8^{+} \mathrm{CD} 62 \mathrm{~L}^{+} \mathrm{T}$ cells, and $\mathrm{CD} 3{ }^{+} \mathrm{CD} 8^{+} \mathrm{CD} 62 \mathrm{~L}$ $\mathrm{T}$ cells.

Enumeration of tumor-infiltrating leukocytes following CCL21 treatment. Panc02 tumors were dissociated $24 \mathrm{~h}$ after the final treatment, and evaluation of phenotypes of infiltrating, non-parenchymal cells by 4-color flow cytometry revealed that $\mathrm{CD}^{+}$lymphocytes, but not $\mathrm{B} 220^{+} \mathrm{B}$ lymphocytes, were significantly increased in number (16-fold) after CCL21 treatment (Fig. 6A). In addition, both NKT cells $\left(\mathrm{NK} 1.1^{+} \mathrm{CD} 3^{+}\right)$ and $\mathrm{NK}$ cells $\left(\mathrm{NK} 1.1^{+} \mathrm{CD}^{-}\right)$were significantly more numerous in the tumors following CCL21 treatment (Fig. 6B).

The increase in $\mathrm{CD}^{+}$cell levels included a significant (26-fold) enhancement in $\mathrm{CD}^{+}{ }^{+} \mathrm{CD} 8{ }^{+}$cell numbers following CCL21 injection, but the difference between CCL21 and PBS treatment group $\mathrm{CD}^{+}{ }^{+} \mathrm{CD} 4{ }^{+}$cell numbers was not significant (Fig. 6C). CD62L has been described as a surface marker displayed on naïve T cells and lost upon their activation (30). Furthermore, expression of CD62L has been shown to correlate with the presence of $\mathrm{CCR} 7$ on both $\mathrm{CD}^{+}$and $\mathrm{CD} 8^{+} \mathrm{T}$ cells, and has previously been used to divide memory $\mathrm{T}$ cells into subsets consisting of central memory cells (CD62 $\left.\mathrm{L}^{\text {high }}\right)$ and effector memory cells (CD62 $\left.\mathrm{L}^{\text {low }}\right)(6,31)$. A subset of $\mathrm{T}$ cells that was $\mathrm{CD}^{+}{ }^{+} \mathrm{CD} 8{ }^{+} \mathrm{CD} 62 \mathrm{~L}^{+}$(presumably naïve or central memory $\mathrm{T}$ cells) was significantly increased in the CCL21treated tumors (Fig. 6C). However, the great majority of T cells in CCL21-treated tumors expressed low levels of CD62L (Fig. 6C), characteristic of activated T cells. PBS-treated tumors had only rare $\mathrm{CD}^{+}$or $\mathrm{CD}^{+}$cells positive for $\mathrm{CD} 62 \mathrm{~L}$, as well as significantly fewer CD62L- cells than their CCL21 counterparts (Fig. 6C). Thus, CCL21 treatment increased intratumoral infiltration by $\mathrm{T}$ cells, particularly those with an activated or mature phenotype.

The expression of IL-2R (CD25) on both $\mathrm{CD} 8^{+}$and $\mathrm{CD} 4^{+}$ $\mathrm{T}$ cells is indicative of $\mathrm{T}$ cell activation, but CD4 and CD25 
A

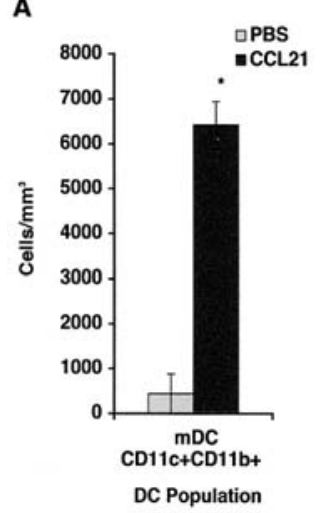

B

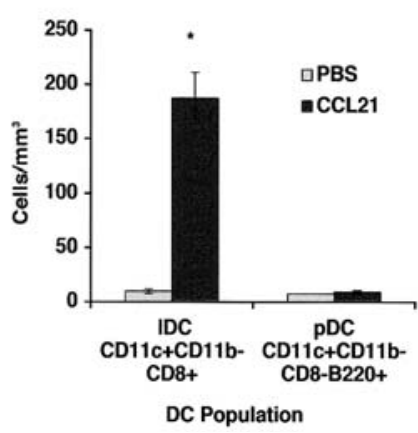

Figure 7. Both $\mathrm{mDC}$ and $1 \mathrm{DC}$ were present in the tumor mass in greater numbers following CCL21 treatments, as shown by flow cytometry on cells from tumors harvested at day 11. Similar data were obtained in three independent experiments. Representative data from one of the three experiments are shown in the graphs. (A) Myeloid DCs (mDC; $\mathrm{CD} 11 \mathrm{c}^{+} \mathrm{CD} 11 \mathrm{~b}^{+}$) were both found to be significantly increased in numbers within the CCL21-treated tumors at day 11. (B) Lymphoid DCs (IDC; $\left.\mathrm{CD} 11 \mathrm{c}^{+} \mathrm{CD} 11 \mathrm{~b}^{-} \mathrm{CD}^{+}\right)$were also significantly increased in CCL21injected tumors upon examination at day 11, but plasmacytoid DC (pDC; $\mathrm{CD} 11 \mathrm{c}^{+} \mathrm{CD} 11 \mathrm{~b}-\mathrm{CD} 8-\mathrm{B} 220^{+}$) were not significantly increased.

are also co-expressed on regulatory $\mathrm{T}$ cells (32). In our study, $\mathrm{CD} 4{ }^{+} \mathrm{CD} 25^{+}$cells were increased 150 -fold in the CCL21treated tumors, relative to PBS-treated tumors (PBS group $3 \pm 3$ cells $/ \mathrm{mm}^{3}$; CCL21 group $471 \pm 46$ cells $\left./ \mathrm{mm}^{3} ; \mathrm{p}<0.05\right)$. In contrast, the number of $\mathrm{CD} 8{ }^{+} \mathrm{CD} 25^{+}$cells in the CCL21treated tumors versus PBS-treated tumors were not significantly different. $\mathrm{CD} 4{ }^{+} \mathrm{CD} 25^{+} \mathrm{T}$ regulatory cells (Tregs) have been divided into subsets according to their expression of CD62L, and although both subsets are suppressive, there is some evidence that the $\mathrm{CD} 62 \mathrm{~L}^{+}$subset has more proliferative potential and sustained suppressive activity $(33,34)$. In our study, the population of $\mathrm{CD} 4{ }^{+} \mathrm{CD} 25^{+}$cells in the treated tumors likely includes both activated effector $\mathrm{T}$ cells and some Tregs. Our future studies will include administration of CD25+ celldepleting antibodies before CCL21 intratumoral injection to test whether allowing development of the effector response unabated by infiltrating Tregs increases the therapeutic effect of CCL21.

DC infiltration of tumors following intratumoral CCL21 treatment. DC subtypes have been proposed to possess intrinsic differences in their ability to polarize $\mathrm{CD}^{+}{ }^{+}$Th cell responses $(35,36)$, and thus potentially to influence anti-tumor responses. In mice, the $\mathrm{mDC}$ subset $\left(\mathrm{CD} 11 \mathrm{c}^{\text {high }} \mathrm{CD} 11 \mathrm{~b}^{\text {high }} \mathrm{CD} 8^{-}\right)$ is associated with IL-10 secretion, and thus with skewing immune responses toward Th2 cell responses (37-39); however, antigen concentration and maturation signals influence the ability of these DC to polarize responses (40). We found that the number of intratumoral $\mathrm{mDC}$ was significantly increased after treatment with CCL21, compared with PBS (Fig. 7A). IL-12 secretion, which augments T and NK cell activity, is thought to be a characteristic of murine IDC $\left(\mathrm{CD} 11 \mathrm{c}^{\text {high }} \mathrm{CD} 11 \mathrm{~b}^{\text {low }} \mathrm{CD} 8^{+}\right)(41,42)$. In addition, IDC are also known to cross-prime effectively (43). LDC were found in very low numbers in tumors from PBS-treated animals, but

were significantly higher in CCL21-treated tumors (Fig. 7B). A third class of DC, the plasmacytoid DC (pDC) subset (defined in mice by $\mathrm{CD} 11 \mathrm{c}^{+} \mathrm{CD} 11 \mathrm{~b}-\mathrm{B} 220^{+}$expression), may suppress anti-tumor $\mathrm{T}$ cell responses (44). The numbers of pDC were very low in both PBS- and CCL21-treated tumors $\left(<10\right.$ cells $\left./ \mathrm{mm}^{3}\right)$ and were unaltered by CCL21 tumor treatment (Fig. 7B).

\section{Discussion}

Our results showing that intratumoral CCL21 injection can slow pancreatic tumor growth extend prior studies of CCL21 treatment for murine models of melanoma, breast cancer, and lung cancer (15-18). Our findings also demonstrate that intratumoral CCL21 injection facilitates systemic immune responses that are cell-mediated and tumor-specific. Thus, CCL21 therapy may be of benefit against metastatic disease, if delivered at the primary pancreatic tumor site as a neoadjuvant treatment (i.e., prior to surgical resection of tumor), or if injected into inoperably large tumors.

We found that CCL21-treated tumors (relative to PBStreated controls) exhibited increased numbers of DC and T cells spread throughout the tumor, as well as clustered together. DC and T cells were especially prevalent in CCL21-treated tumors in areas of vascularization, although overall tumor vascularization in these tumors was reduced (perhaps because of angiostatic effects and/or limited tumor size). The DC infiltrating the tumor following CCL21 injection may facilitate $\mathrm{T}$ cell anti-tumor responses through extranodal $\mathrm{T}$ cell stimulation (20), as well as by presentation of relevant tumor antigen following migration to regional $\mathrm{LN}$ (26). Within the leukocytic aggregates in CCL21-treated tumors, CD11 $\mathrm{c}^{+}$DC cells were also found co-localized with NK cells.

Our data found both IDC and, to a greater extent, mDC were introduced in significant numbers to the tumor microenvironment following CCL21 injection. Past studies have shown murine IDC to be a DC subset that is highly effective at IL-12 and interferon- $\gamma$ secretion, and are thus expected to be beneficial for efficient local anti-tumor responses $(37,45)$. However, the recent demonstrated ability of $\mathrm{mDC}$ to polarize Th1 after appropriate activation via specific Toll-like receptors and high antigen levels (40) suggests that targeting of intratumoral $\mathrm{mDC}$ with specific Toll-like receptor ligands following CCL21 injection may be an especially effective immunotherapeutic approach.

The majority of $\mathrm{CD}^{+}$cells found within treated tumors on day 11 post-treatment initiation displayed an activated/mature phenotype, in that they lacked the expression of CD62L $(2,30)$. However, significant tumor growth inhibition started as early as day 4 post-start of therapy, allowing little time for DC priming of a de novo anti-tumor response. This rapid onset of inhibition suggests that CCL21 recruitment of $\mathrm{CD}^{+}$central memory cells, which express CCR7 and are capable of rapid activation upon detection of antigen (31), may be a significant contributor to early CCL21-induced anti-tumor responses.

Also in the present study, we found both NK and NKT cells infiltrated the Panc02 tumor in significantly increased numbers. NK and NKT cells have been observed to undergo chemotaxis in response to CCL21, especially the CD56 $6^{\text {bright }} \mathrm{CD} 16$ population in humans $(4,46)$. A previous antibody depletion 
study suggested that NK cells, as well as T cells, play a role in CCL21-facilitated immunological responses (14). However, to our knowledge, our study is the first to identify NK and NKT cells infiltrating the CCL21-treated tumor mass.

The inability of injected CCL21 to reduce tumor growth in $R A G 2^{-/} P f p^{-/}$mice suggests that direct angiostatic effects, if any, were insufficient to have therapeutic impact. Previous studies suggesting a direct angiostatic mechanism for CCL21 $(14,47)$ were distinct from our study in that they used mouse models (SCID and nu/nu) that, although lacking B cells and T cells, still possess fully functional NK cells. Thus, NK cells should be considered as a potentially critical contributor to the mechanism underlying CCL21's ability to slow tumor growth.

In conclusion, several of our findings support the development of CCL21 as a treatment for pancreatic cancer that acts through in vivo manipulation of immune cell populations. CCL21 was demonstrated to recruit immune cells known to be contributory to anti-tumor responses (DC, T cells, NK cells, and NKT cells) into the tumor. Our observations, coupled with previous data indicating that the level of $\mathrm{T}$ cell and DC infiltration is predictive of the duration of survival for pancreatic cancer patients (50), suggest that CCL21 may be of potential value in the neoadjuvant setting and/or for the treatment of non-resectable primary pancreatic tumors and metastases.

\section{Acknowledgements}

This study was funded by an LB595/Cattlemen's Grant (J.C.S.), the NRI Molecular Therapeutics Program (J.E.T., J.C.S., R.K.S. and M.A.H.), and NIH Grant P50 CA72712 (M.A.H. and J.C.S.). H.R.T. received support from the NIH Training Grant T32 CA09476, and H.R.T. and A.E.A. were supported by UNMC Graduate and Presidential Fellowships and by DOD Breast Cancer Research Program Fellowships. Assistance was provided by the UNMC Animal Facility, Cell Analysis Facility, and Confocal Laser Scanning Microscope Core Facility. We thank M. McIhaney, M. Varney, and E. Benner for technical advice.

\section{References}

1. Gunn MD, Kyuwa S, Tam C, Kakiuchi T, Matsuzawa A, Williams LT and Nakano H: Mice lacking expression of secondary lymphoid organ chemokine have defects in lymphocyte homing and dendritic cell localization. J Exp Med 189: 451-460, 1999.

2. Bjorkdahl O, Barber KA, Brett SJ, Daly MG, Plumpton C, Elshourbagy NA, Tite JP and Thomsen LL: Characterization of $\mathrm{CC}$-chemokine receptor 7 expression on murine $\mathrm{T}$ cells in lymphoid tissues. Immunology 110: 170-179, 2003.

3. Dieu MC, Vanbervliet B, Vicari A, Bridon JM, Oldham E, Ait-Yahia S, Briere F, Zlotnik A, Lebecque S and Caux C: Selective recruitment of immature and mature dendritic cells by distinct chemokines expressed in different anatomic sites. J Exp Med 188: 373-386, 1998.

4. Johnston B, Kim CH, Soler D, Emoto M and Butcher EC: Differential chemokine responses and homing patterns of murine TCR alpha beta NKT cell subsets. J Immunol 171: 2960-2969, 2003.

5. Kim CH, Johnston B and Butcher EC: Trafficking machinery of NKT cells: shared and differential chemokine receptor expression among V alpha $24(+) \mathrm{V}$ beta $11(+)$ NKT cell subsets with distinct cytokine-producing capacity. Blood 100: 11-16, 2002.
6. Sallusto F, Lenig D, Forster R, Lipp M and Lanzavecchia A: Two subsets of memory $\mathrm{T}$ lymphocytes with distinct homing potentials and effector functions. Nature 401: 708-712, 1999.

7. Vitale M, Della Chiesa M, Carlomagno S, Romagnanci C, Thiel A, Moretta L and Moretta A: The small subset of CD56brightCD16-natural killer cells is selectively responsible for both cell proliferation and interferon-gamma production upon interaction with dendritic cells. Eur J Immunol 34: 1715-1722, 2004

8. Yoshida R, Imai T, Hieshima K, Kusuda J, Baba M, Kitaura M, Nishimura M, Kakizaki M, Nomiyama $\mathrm{H}$ and Yoshie O: Molecular cloning of a novel human CC chemokine EBI1-ligand chemokine that is a specific functional ligand for EBI1, CCR7. J Biol Chem 272: 13803-13809, 1997.

9. Yoshida R, Nagira M, Imai T, Baba M, Takagi S, Tabira Y, Akagi J, Nomiyama $\mathrm{H}$ and Yoshie O: EBI1-ligand chemokine (ELC) attracts a broad spectrum of lymphocytes: activated T cells strongly up-regulate CCR7 and efficiently migrate toward ELC. Int Immunol 10: 901-910, 1998.

10. Gunn MD, Tangemann K, Tam C, Cyster JG, Rosen SD and Williams LT: A chemokine expressed in lymphoid high endothelial venules promotes the adhesion and chemotaxis of naïve T lymphocytes. Proc Natl Acad Sci USA 95: 258-263, 1998.

11. Stein JV, Rot A, Luo Y, Narasimhaswamy M, Nakano H, Gunn MD, Matsuzawa A, Quackenbush EJ, Dorf ME and von Andrian UH: The CC chemokine thymus-derived chemotactic agent 4 (TCA-4, secondary lymphoid tissue chemokine, 6Ckine, exodus-2) triggers lymphocyte function-associated antigen 1-mediated arrest of rolling T lymphocytes in peripheral lymph node high endothelial venules. J Exp Med 191: 61-76, 2000.

12. Yanagawa $\mathrm{Y}$ and Onoe K: CCR7 ligands induce rapid endocytosis in mature dendritic cells with concomitant up-regulation of Cdc42 and Rac activities. Blood 101: 4923-4929, 2003.

13. Soto H, Wang W, Strieter RM, Copeland NG, Gilbert DJ, Jenkins NA, Hedrick J and Zlotnik A: The CC chemokine 6Ckine binds the CXC chemokine receptor CXCR3. Proc Natl Acad Sci USA 95: 8205-8210, 1998

14. Vicari AP, Ait-Yahia S, Chemin K, Mueller A, Zlotnik A and Caux C: Antitumor effects of the mouse chemokine 6Ckine/ SLC through angiostatic effects of the mouse chemokine 6Ckine/SLC through angiostatic and immunological mechanisms. J Immunol 165: 1992-2000, 2000.

15. Kirk CJ, Hartigan-O'Connor D, Nickoloff BJ, Chamberlain JS, Giedlin M, Aukerman L and Mule JJ: T cell-dependent antitumor immunity mediated by secondary lymphoid tissue chemokine: augmentation of dendritic cell-based immunotherapy. Cancer Res 61: 2062-2070, 2001.

16. Sharma S, Stolina M, Luo J, Strieter RM, Burdick M, Zhu LX, Batra RK and Dubinett SM: Secondary lymphoid tissue chemokine mediates $\mathrm{T}$ cell-dependent antitumor responses in vivo. $\mathrm{J}$ Immunol 164: 4558-4563, 2000.

17. Sharma S, Stolina M, Zhu L, Lin Y, Batra R, Huang M, Strieter R and Dubinett SM: Secondary lymphoid organ chemokine reduces pulmonary tumor burden in spontaneous murine bronchoalveolar cell carcinoma. Cancer Res 61: 6406-6412, 2001.

18. Sharma S, Yang SC, Hillinger S, Zhu LX, Huang M, Batra RK, Lin JF, Burdick MD, Strieter RM and Dubinett SM: SLC/ CCL21-mediated anti-tumor responses require IFNgamma, MIG/CXCL9 and IP-10/CXCL10. Mol Cancer 2: 22, 2003.

19. Yang SC, Hillinger S, Riedl K, Zhang L, Zhu L, Huang M, Atianzar K, Kuo BY, Gardner B, Batra RK, Strieter RM, Dubinett SM and Sharma S: Intratumoral administration of dendritic cells overexpressing CCL21 generates systemic antitumor responses and confers tumor immunity. Clin Cancer Res 10: 2891-2901, 2004.

20. Kirk CJ, Hartigan-O'Connor D and Mule JJ: The dynamics of the T-cell antitumor response: chemokine-secreting dendritic cells can prime tumor-reactive T cells extranodally. Cancer Res 61: 8794-8802, 2001.

21. Cancer FACTS and Figures. American Cancer Society, Atlanta, GA, 2004.

22. Li D, Xie K, Wolff R and Abbruzzese JL: Pancreatic cancer. Lancet 363: 1049-1057, 2004.

23. Fukunaga A, Miyamoto M, Cho Y, Murakami S, Kawarada Y, Oshikiri T, Kato K, Kurokawa T, Suzuoki M, Nakakubo Y, Hiraoka K, Itoh T, Morikawa T, Okushiba S, Kondo S and Katoh H: CD8+ tumor-infiltrating lymphocytes together with CD4+ tumor-infiltrating lymphocytes and dendritic cells improve the prognosis of patients with pancreatic adenocarcinoma. Pancreas 28: 326-331, 2004. 
24. Dallal RM, Christakos P, Lee K, Egawa S, Son YI and Lotze MT: Paucity of dendritic cells in pancreatic cancer. Surgery 131: 135-138, 2002.

25. Fonteneau JF, Kavanagh DG, Lirvall M, Sanders C, Cover TL, Bhardwaj N and Larsson M: Characterization of the MHC class I cross-presentation pathway for cell-associated antigens by human dendritic cells. Blood 102: 4448-4455, 2003.

26. Guiducci C, Di Carlo E, Parenza M, Hitt M, Giovarelli M, Musiani $\mathrm{P}$ and Colombo MP: Intralesional injection of adenovirus encoding CC chemokine ligand 16 inhibits mammary tumor growth and prevents metastatic-induced death after surgical removal of the treated primary tumor. J Immunol 172: 4026-4036, 2004.

27. Corbett TH, Roberts BJ, Leopold WR, Peckham JC, Wilkoff LJ, Griswold DP Jr and Schabel FM Jr: Induction and chemotherapeutic response of two transplantable ductal adenocarcinomas of the pancreas in C57BL/6 mice. Cancer Res 44: 717-726, 1984.

28. Winn HJ: Immune mechanisms in homotransplantation. II. Quantitative assay of the immunologic activity of lymphoid cells stimulated by tumor homografts. J Immunol 86: 228-239, 1961.

29. Vremec D and Shortman K: Dendritic cell subtypes in mouse lymphoid organs: cross-correlation of surface markers, changes with incubation, and differences among thymus, spleen, and lymph nodes. J Immunol 159: 565-573, 1997.

30. Jung TM, Gallatin WM, Weissman IL and Dailey MO: Downregulation of homing receptors after $\mathrm{T}$ cell activation. J Immunol 141: 4110-4117, 1988.

31. Unsoeld H, Krautwald S, Voehringer D, Kunzendorf U and Pircher H: Cutting edge: CCR7+ and CCR7- memory T cells do not differ in immediate effector cell function. J Immunol 169: 638-641, 2002.

32. Shimizu J, Yamazaki S and Sakaguchi S: Induction of tumor immunity by removing CD25+CD4+ T cells: a common basis between tumor immunity and autoimmunity. J Immunol 163: 5211-5218, 1999

33. Fu S, Yopp AC, Mao X, Chen D, Zhang N, Mao M, Ding Y and Bromberg JS: CD4+CD25+CD62+ T-regulatory cell subset has optimal suppressive and proliferative potential. Am J Transplant 4: 65-78, 2004.

34. You S, Slehoffer G, Barriot S, Bach JF and Chatenoud L: Unique role of $\mathrm{CD} 4+\mathrm{CD} 62 \mathrm{~L}+$ regulatory $\mathrm{T}$ cells in the control of autoimmune diabetes in $\mathrm{T}$ cell receptor transgenic mice. Proc Natl Acad Sci USA 101 (Suppl 2): 14580-14585, 2004.

35. O'Keeffe M, Hochrein H, Vremec D, Scott B, Hertzog P, Tatarczuch L and Shortman K: Dendritic cell precursor populations of mouse blood: identification of the murine homologues of human blood plasmacytoid pre-DC2 and CD11c+ DC1 precursors. Blood 101: 1453-1459, 2003.
36. Whiteside TL and Odoux C: Dendritic cell biology and cancer therapy. Cancer Immunol Immunother 53: 240-248, 2004.

37. Maldonado-Lopez R, Maliszewski C, Urbain J and Moser M: Cytokines regulate the capacity of CD8alpha(+) and CD8alpha(-) dendritic cells to prime Th1/Th2 cells in vivo. J Immunol 167: 4345-4350, 2001.

38. Pulendran B, Smith JL, Caspary G, Brasel K, Pettit D, Maraskovsky E and Maliszewski CR: Distinct dendritic cell subsets differentially regulate the class of immune response in vivo. Proc Natl Acad Sci USA 96: 1036-1041, 1999.

39. Rissoan MC, Soumelis V, Kadowaki N, Grouard G, Briere F, de Waal, Malefyt R and Liu YJ: Reciprocal control of T helper cell and dendritic cell differentiation. Science 283: 1183-1186, 1999.

40. Boonstra A, Asselin-Paturel C, Gilliet M, Crain C, Trinchieri G, Liu YJ, and O'Garra A: Flexibility of mouse classical and plasmacytoid-derived dendritic cells in directing $\mathrm{T}$ helper type 1 and 2 cell development: dependency on antigen dose and differential toll-like receptor ligation. J Exp Med 197: 101-109, 2003.

41. Barth RJ Jr, Mule JJ, Spiess PJ and Rosenberg SA: Interferon gamma and tumor necrosis factor have a role in tumor regressions mediated by murine CD8+ tumor-infiltrating lymphocytes. J Exp Med 173: 647-658, 1991.

42. Grufman P and Karre K: Innate and adaptive immunity to tumors: IL-12 is required for optimal responses. Eur J Immunol 30: 1088-1093, 2000.

43. den Haan JM, Lehar SM and Bevan MJ: CD8(+) but not CD8(-) dendritic cells cross-prime cytotoxic T cells in vivo. J Exp Med 192: 1685-1696, 2000.

44. Nakano H, Yanagita M and Gunn MD: CD11c(+)B220(+)Gr-1(+) cells in mouse lymph nodes and spleen display characteristics of plasmacytoid dendritic cells. J Exp Med 194: 1171-1178, 2001.

45. Tatsumi T, Kierstead LS, Ranieri E, Gesualdo L, Schena FP, Finke JH, Bukowski RM, Mueller-Berghaus J, Kirkwood JM, Kwok WW and Storkus WJ: Disease-associated bias in Thelper type 1 (Th1)/Th2 CD4(+) T cell responses against MAGE-6 in HLA-DRB10401(+) patients with renal cell carcinoma or melanoma. J Exp Med 196: 619-628, 2002.

46. Kim CH, Pelus LM, Appelbaum E, Johanson K, Anzai N and Broxmeyer HE: CCR7 ligands, SLC/6Ckine/Exodus2/TCA4 and CKbeta-11/MIP-3beta/ELC, are chemoattractants for CD56(+)CD16(-) NK cells and late stage lymphoid progenitors. Cell Immunol 193: 226-235, 1999.

47. Arenberg DA, Zlotnick A, Strom SR, Burdick MD and Strieter RM: The murine CC chemokine, 6C-kine, inhibits tumor growth and angiogenesis in a human lung cancer SCID mouse model. Cancer Immunol Immunother 49: 587-592, 2001. 